\title{
Foreign Body Aspiration in Children; Analysis of 42 Cases
}

\section{Tulin Durgun Yetim ${ }^{1}$, Hanifi Bayarogulları², Vefik Arıca ${ }^{3 *}$, Bülent Akcora ${ }^{4}$, Secil Gunher Arıca ${ }^{5}$ and Murat Tutanc ${ }^{3}$}

${ }^{1}$ Thoracic Surgery Department, Mustafa Kemal University, Hatay, Turkey

${ }^{2}$ Radiology Department, Mustafa Kemal University, Hatay, Turkey

${ }^{3}$ Pediatric Department, Mustafa Kemal University, Hatay, Turkey

${ }^{4}$ Pediatric Surgery Department, Mustafa Kemal University, Hatay, Turkey

${ }^{5}$ Family Medicine Department, Mustafa Kemal University, Hatay, Turkey

\section{Abstract}

Aim: Tracheal foreign body aspiration is among the major causes of death in developing countries, specifically in infancy and childhood. If it is diagnosed in early period and the foreign body is removed, no complication develops.

Material \& Method: Records of 42 forensic child patients who applied to Mustafa Kemal University, Medical Faculty Hospital and the Antakya State Hospital, Thoracic Surgery and Pediatric Surgery clinics between 2008-2011, and hospitalized with the thraceobronchial foreign body aspiration prediagnosis were studied retrospectively.

Results: Of the 42 patients, 22 were male and 20 were female, and their ages ranged from 4 months to 5 years. Foreign body was detected in 38 cases. In 4 cases, bronchoscopy was performed with the suspicion of foreign body, but no foreign body was observed. The foreign body was removed with rigid bronchoscopy in 37 cases, and in one case, metal tip of a pen was removed from left upper lobe bronchus with thoracotomy.

Conclusion: Foreign body aspirations in children mostly originate from accidents. Similarly, the cause of aspiration in children under the age of 5 in our study was mainly accidental and the rest were due to the negligence.

Keywords: Foreign body; Aspiration; Bronchoscopy; Children

\section{Introduction}

Tracheobronchial foreign body aspiration can lead to fatal acute respiratory failure when it causes near-complete occlusion at the tracheal level. However, the foreign bodies that have managed to proceed to the lower levels of the tracheobronchial tree can cause to respiratory tract problems at the distal of the region they occluded, because occlusion leads to ventilation failure which creates a favorable environment for infection $[1,2]$.

The children aged between $0-3$ constitute more than $75 \%$ of the foreign body aspiration cases. Furthermore, foreign body aspiration constitutes $7 \%$ of the deaths among the children aged $0-3[3,4]$. In developing countries, foreign body aspiration is among the major causes of death in infancy and childhood $[5,6]$. It can cause symptoms like coughing, difficulty in breathing and hoarse voice in the early period, and complications like obstructive emphysema, atelectasis, lung abscess, empyema, bronchiectasis or pneumothorax in the late period. All these symptoms and complications may lead to complaints like recurrent infections, hemoptysis or bronchial asthma $[5,6]$. While a large foreign body can cause a sudden death by occluding the respiratory tract completely, a small foreign object may also result in death by causing first laryngospasm and then hypoxic crisis $[5,6]$.

When the foreign body is diagnosed and removed in the early period, no complications develop [7-9]. This study aimed to investigate the cases of foreign body aspiration.

\section{Material and Method}

The records of 42 forensic children who were hospitalized with the tracheobronchial foreign body aspiration prediagnosis in Mustafa Kemal University, Medical Faculty Hospital and in the Antakya State Hospital, Thoracic Surgery and Pediatric Surgery clinics between 20082011 were studied retrospectively.

In the study, the patients were evaluated for age, gender, where and when they presented to the hospital, complaints, duration of admittance to the hospital, physical examination findings, radiological findings, characteristics and location of the foreign body, treatment methods, complications and mortality.

Rigid bronchoscopy under general anesthesia, patients were shortactinganesthetics. During the removal/aspiration of the foreign body, the anaesthesia team is requested to reduce the ventilation of the lungs. Thus, it is possible to prevent the foreign body displacements.

\section{Results}

Of the patients whose ages range between 4 months and 5 years, 20 (47\%) were female and 22 (53\%) were male. Foreign body was identified in 38 patients out of 42 . Four patients underwent bronchoscopy with the suspicion of foreign body but no foreign body was observed. Negative bronchoscopy cases were mostly the patients who were suspected to have foreign bodies such as dried fruits or nuts. The patients might have suspected to swallow a foreign body although they had swallowed only the secretion.

Of the patients, 22 (53\%) had cough, 7 (17\%) had dyspnea, 3 had (8\%) wheezing, 2 (4\%) had cyanosis, 2 (4\%) had foam at mouth and $1(\% 2)$ had recurrent pulmonary infections. In 5 patients, no symptoms were observed. Foreign bodies were removed with rigid bronchoscopy in 37 patients (88\%). In 1 case (2\%), a metal pen tip was removed from the left upper lobe bronchus with thoracotomy. Thirty patients (74\%) presented to the hospital within the first 6 hours, $8(22 \%)$ within the first 24 hours, 2 (4\%) within the first 15 days and 2 (4\%) in a period over 1 month. Duration of admittance to the hospital is given in Table 1.

*Corresponding author: Dr. Vefik ARICA, Mustafa Kemal University Medical Faculty, The chair of Pediatric Clinic, 31100, Hatay, Turkey, Tel: +90505 6797877; E-mail: vefikarica@hotmail.com

Received March 26, 2012; Accepted April 13, 2012; Published April 15, 2012

Citation: Yetim TD, Bayarogulları H, Arıca V, Akcora B, Arıca SG, et al. (2012) Foreign Body Aspiration in Children; Analysis of 42 Cases. J Pulmon Resp Med 2:121. doi:10.4172/2161-105X.1000121

Copyright: ( 2012 Yetim TD, et al. This is an open-access article distributed under the terms of the Creative Commons Attribution License, which permits unrestricted use, distribution, and reproduction in any medium, provided the original author and source are credited. 
The children who presented after a month's period had been repeatedly treated by the pediatric outpatient clinics for pulmonary infections, but they had not responded to the treatments and had been directed for bronchoscopy. The period between the aspiration history and treatment ranged from 1 hour to 1 month (Table 1). The patients who had more irritating objects, such as beads or pins admitted to the clinics earlier. Posteroanterior chest radiography and chest CT findings of the children are given in Table 2. The foreign body localizations identified by bronchoscopy are shown in Table 3 . The foreign bodies were located in the main bronchus of the right bronchial system in 19 cases (50\%) and of the left bronchial system in 17 cases (44\%). Additionally, it was detected in 2 cases that foreign bodies were located in the trachea.

The foreign objects identified in the tracheobronchial system and removed successfully were as follows; dried nuts or seeds in 20 cases (Figure 1-4), led bulb in 1 case (Figure 5 and 6), bead-headed pins in 3 cases, coin in 1 case, buttons and press studs in 3 cases, beads in 3 cases, metal tip of a pencil in 1 case (Figure 7), corn in 3 cases, safety pin in 1 case, chicken bone in 1 case (Figure 8 and 9) and a piece of a plastic toy in 1 patient. The foreign body was removed via rigid bronchoscopy with the help of forceps in 37 cases (88\%). In one case (2\%), the foreign body was removed with thoracotomy because the extraction of the foreign body that completely blocked the right main bronchus could not be achieved. Thus, thoracotomy + bronchotomy were performed to remove the metal tip of a pen. The foreign bodies identified in patients are given in Table 4 .

\section{Discussion}

Bronchoscopy is the observation of tracheobronchial tree both for the diagnostic purpose and for the treatment. Observation with rigid bronchoscopy still preserves its vital importance in removing the foreign bodies in the tracheobronchial tree.

In practice, fiber-optic bronchoscope has no superiority to rigid bronchoscope in removing foreign bodies $[1,10]$. Bronchoscopy should

\begin{tabular}{|l|c|}
\hline Admission Time & Number of patients \\
\hline 6 hours & 30 \\
\hline 24 hours & 8 \\
\hline 15 days & 2 \\
\hline More than 1 month & 2 \\
\hline
\end{tabular}

Table 1: Admission time of patients

\begin{tabular}{|l|c|}
\hline Chest x-ray and Thorax CT Results & Number of patients \\
\hline Radiopaque foreign body & 25 \\
\hline Obstructive emphysema & 8 \\
\hline Atelectasis & 3 \\
\hline Pneumonic infiltration & 1 \\
\hline Normal image & 5 \\
\hline
\end{tabular}

Table 2: PA x-ray and Thorax CT results of the patients.

\begin{tabular}{|l|c|c|c|c|}
\hline $\begin{array}{l}\text { Foreign body } \\
\text { localizations }\end{array}$ & $\begin{array}{c}\text { Right bronchial } \\
\text { system }\end{array}$ & $\begin{array}{c}\text { Left bronchial } \\
\text { system }\end{array}$ & Trachea & Total \\
\hline Main bronchus & 11 & 10 & 2 & \\
\hline Upper lobe & 4 & 3 & & \\
\hline $\begin{array}{l}\text { Intermediary } \\
\text { bronchus }\end{array}$ & 2 & 3 & & \\
\hline Middle lobe & 1 & 1 & & \\
\hline Lower lobe & 1 & 17 & 2 & 38 \\
\hline No. of patients & 19 & 17 & & \\
\hline
\end{tabular}

Table 3: Localizations of the foreign objects identified via bronchoscopy.

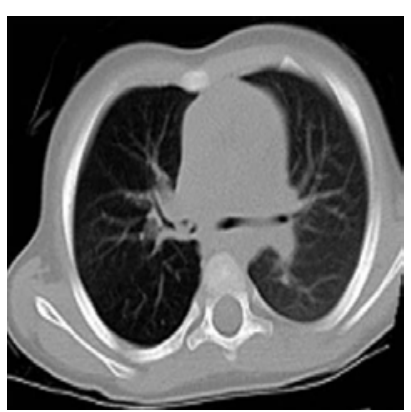

Figure 1: Axial CT section obtained with the parenchyma window; foreign body in the right main bronchus. After bronchoscopy, the object was identified to be a piece of peanut.

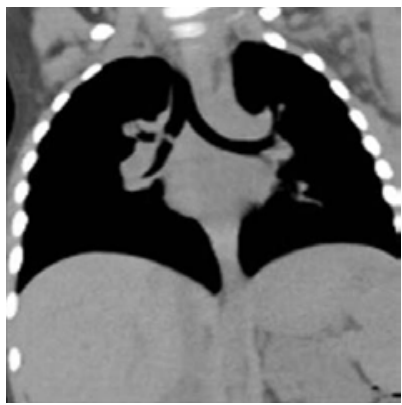

Figure 2: Coronal CT section obtained with mediastinal window; foreign body in soft tissue density of right main bronchus. After bronchoscopy, the object was identified to be a piece of peanut.

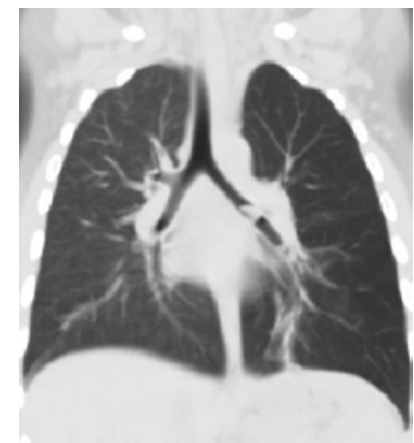

Figure 3: Coronal and axial CT section obtained with the parenchyma window foreign body in the left main bronchus, causing an increase in the aeration of the left lung (a piece of peanut was identified in bronchoscopy).

be performed in all cases with the suspicion of foreign body aspiration. Observation via bronchoscope has almost no risk of morbidity with experienced personnel. However, if the operation is performed by inexperienced personnel, or if the personnel get into panic, the process may become life-threatening. Foreign body aspiration is a serious condition which may potentially result in death.

Foreign body aspirations can be seen at any age, however, it has been reported to be observed under the age of $3(73 \%)$ and particularly in children aged 1-3 [1,11,12]. Gürses et al. [13] reported that $84 \%$ of the patients were under the age of three. The incidence is high in this age group because the teeth cannot chew effectively and consequently the food kept in mouth longer than normal may lead to the aspiration of solid material. Another significant reason increasing the incidence of aspiration is that the children under the age of two try to recognize 


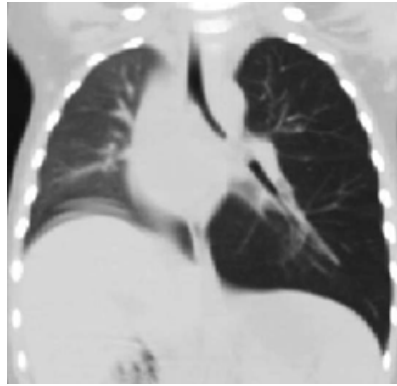

Figure 4: Coronal and axial CT section obtained with the parenchyma window foreign body in the left main bronchus, causing a significant increase in the aeration of the left lung and a mediastinal shift (a piece of dried fruit was identified in bronchoscopy).

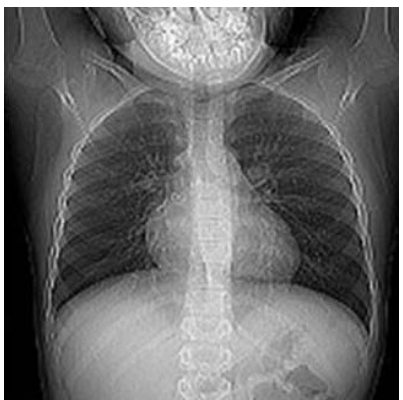

Figure 5: PA Chest x-ray; a hyperdense lesion in the main bronchus at the right hilar area. A led bulb was identified in bronchoscopy.

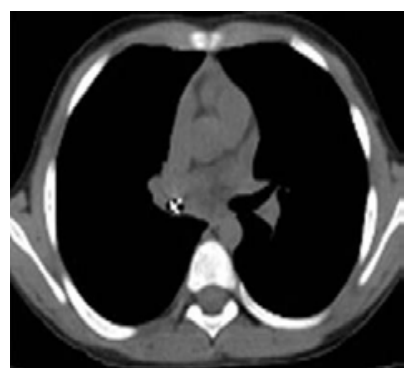

Figure 6: Axial CT section obtained with mediastinal window; a hyperdense lesion in the right bronchus. A led bulb was identified in bronchoscopy.

almost every object by mouthing [14]. Due to the delays in diagnosis, morbidity and mortality rates increase $[6,9,15]$.

Foreign body aspiration is closely related to the age, gender, occupation, cultural life, socioeconomic status, traditions and customs. Foreign body aspiration is high particularly in developing countries due to inadequate education and negligence [16]. It has been reported that males suffer from foreign body aspiration more for unexplained reasons. The ratio is approximately $2 / 1[2,9,14,17]$. In one study, the male / female ratio was reported as 1.2/1 [15,17], while another study reported as $1.5 / 1[13,18]$. Consistent with the literature, it was more common in boys in our study, too.

The nature of the aspirated foreign body affects the clinical picture. Inorganic foreign bodies may cause a sudden blockage in the tracheobronchial system [18]. Organic substances (chickpeas, corn grains) may enlarge due to the moisture in the medium and may tear their capsule. Thus they may easily be broken into pieces during bronchoscopic removal process. In our study, $54 \%$ of the foreign bodies were organic substances (dried nuts and fruit, corn, etc.). In a series of 2170 patients, it was reported that 12 patients needed tracheostomy and 10 patients developed cardiac arrest, and 2 of them died $[6,19]$. No tracheostomy was needed in our cases. No mortality occurred in the bronchoscopy or thoracotomy processes. While the foreign body aspirations in underdeveloped countries are mostly due to organic substances, particularly the nuts or nut shells (shells of peanut, hazelnut, etc.), in developed countries, the incidence of plastic foreign body aspirations have increased in recent years $[16,19]$. It was reported in one study that the $66.3 \%$ of the aspirated foreign bodies was seeds of watermelon, which is a highly consumed fruit in summer [19]. However, Pasaoglu et al. [20] reported that in the study they conducted on children, the most commonly aspirated foreign body was dried nuts and fruit, particularly the sunflower seeds with the rate of $21.5 \%$.

The most commonly aspirated foreign bodies in children are

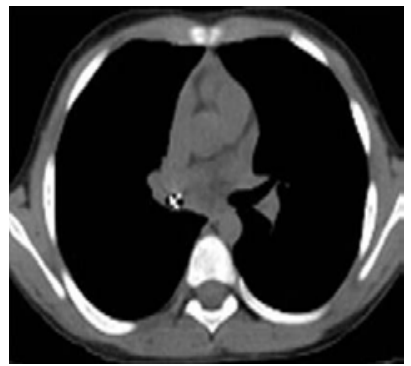

Figure 7: PA Chest x-ray; a rod-shaped hyperdense lesion superposed with mediastinal shadow in the right main bronchus in right hemithorax. Metal tip of a pencil was identified in bronchoscopy.

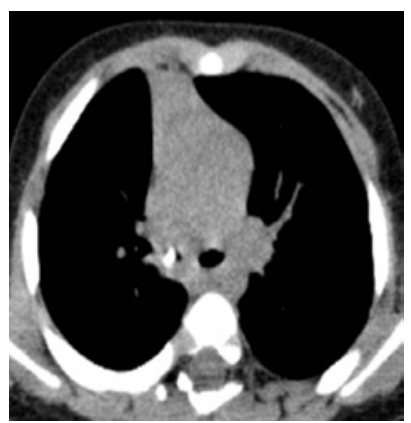

Figure 8: Axial CT section obtained with mediastinal window; a hyperdense lesion in the bronchus of right lower lobe, causing complete obstruction and atelectasis in lower lobe. Chicken bone was identified in bronchoscopy.

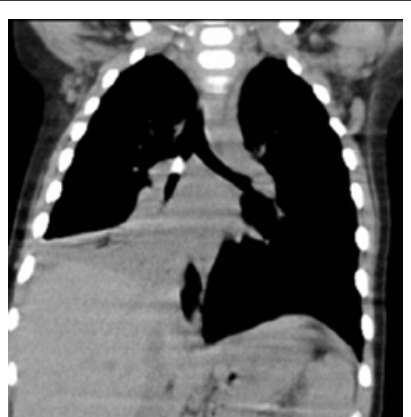

Figure 9: Coronal CT section obtained with mediastinal window; a hyperdense lesion in the bronchus of right lower lobe, causing lower lobe atelectasis. Chicken bone was identified in bronchoscopy. 


\begin{tabular}{|l|c|}
\hline Identified Foreign bodies & No. of patients \\
\hline Dried nuts and fruit & 20 \\
\hline Bead-headed pins & 3 \\
\hline coin & 1 \\
\hline Button, press stud & 3 \\
\hline Bead & 3 \\
\hline Metal pencil tip & 1 \\
\hline Corn & 3 \\
\hline Safety pin & 1 \\
\hline Chicken bone & 1 \\
\hline Led bulb & 1 \\
\hline Plastic toy piece & 1 \\
\hline
\end{tabular}

Table 4: Foreign bodies identified in patients.

such foods as peanuts, hazelnuts, roasted chickpeas or corn. These substances absorb water and enlarge in time, and thus become more easily breakable. Although they are asymptomatic at baseline, this kind of foreign body aspirations can soon cause very serious complications because of this characteristic. Furthermore, because of the same characteristic, these foreign bodies can easily be broken into pieces and progress into more distant airways during endoscopic intervention, and may become inaccessible. Researchers have recommended the use of corticosteroids before and after bronchoscopy to reduce the incidence of postoperative subglottic edema, which may require urgent tracheostomy $[9,14,20]$. Thus, all patients in our study received steroid therapy for 24 hours prior to the bronchoscopy.

Such complications as pneumomediastinum, thoracotomy due to failure in removing the foreign body, laryngeal edema, bronchospasm, endobronchial hemorrhage, pneumothorax or cardiac arrest can also be observed in the early period of foreign body aspirations $[9,14,17,20]$.

Foreign body aspiration should also be considered in patients with recurrent pneumonia and asymptomatic chest X-ray $[16,17,18,20]$. The detailed anamnesis of the patient and the correct localization of the foreign body via physical examination and radiological methods are significant for the diagnosis. In the anamnesis, declaration of a foreign object that the children played could be a significant clue. Foreign body suspicion is the most important step in such cases. Decreased breath sound on the affected side is the most common manifestation in physical examination. Chest $\mathrm{x}$-rays of both sides taken prior to bronchoscopy mostly provide true localization [20,21]. Ten percent of the patients may have normal chest $\mathrm{x}$-rays. It is beneficial to see the mediastinal shift and atelectatic areas in inspiratory and expiratory $\mathrm{x}$-rays taken separately. In our study, $88 \%$ of the patients with tracheobronchial foreign body aspiration shared the same radiological findings as the ones in the literature.

There is a consensus that foreign body aspirations occur mainly in the right main bronchus and its branches due to the anatomical structure of the bronchial tree $[14,20]$. Tracheobronchial foreign body aspiration is most often observed in the right bronchial system. It is due to the fact that the right main bronchus is shorter, wider and more vertical, i.e., closer to the trachea than the left. It has been reported in the literature that $49.4 \%$ of the aspirated foreign bodies is located in the right system, particularly in the right main bronchus $[1,20]$. In our study, too, $50 \%$ of the aspirated foreign bodies were located in the right bronchial tract.

Studies have reported that there might be inevitable negative bronchoscopy. The reported negative bronchoscopy rates in these studies were respectively $8.5 \%, 15.8 \%$ and $10.6 \%$ [15,20-25]. This rate was $11 \%$ in our study. It has been emphasized in the literature that all patients with a history of foreign body aspiration must undergo bronchoscopy and that negative bronchoscopy is inevitable to prevent the morbidity which may arise from the unnoticed foreign bodies $[20,24]$.

Negligence is the situation in which a child's basic needs such as nourishment, health, housing, clothing, protection and supervision cannot be met by parents, or in a wider sense, by the government which is responsible for the health, education, social assistance and security. Negligence may manifest in physical, emotional and/or medical forms. A high degree of negligence can result in death $[20,25,26]$.

Consequently, foreign body aspirations in children are mostly accidental. In our study, the aspirations in children under the age of 5 were also mainly accidental or due to negligence, and since they had demonstrative radiological images, they were considered to be worthy for presentation.

\section{References}

1. Esener Z, Sahinoglu H, Yuksel M, Guney E (1986) Foreign body aspiration bronchoscopy and anesthesia applied problems. Ondokuz Mayis University Journal of Medicine 3: 93-103.

2. Mantel K, Butenandt I (1986) Tracheobronchial foreign body aspiration in childhood. A report on 224 cases. Eur J Pediatr 145: 211-216.

3. Steen KH, Zimmermann T (1990) Tracheobronchial aspiration of foreign bodies in children: a study of 94 cases. Laryngoscope 100: 525-530.

4. Mantor PC, Tuggle DW, Tunell WP (1989)An appropriate negative bronchoscopy rate in suspected foreign body aspiration. Am J Surg 158: 622-624.

5. Smitheringale $A$ (1995) Management of foreign bodies of the tracheobronchial tree. In Pearson (ed). Thoracic surgery. Philadelphia, Churchil Livingstone 1591-1599.

6. Elhassani NB (1988) Tracheobronchial foreign bodies in the Middle East. A Baghdad study. J Thorac Cardiovasc Surg 96: 621-625.

7. Yalcinkaya I (2003) Tracheobronchial foreign body aspiration. In: Okten I, Gungor A (eds), Thoracic surgery 1 (stedn), Ankara 689-698.

8. Yildizeli B, Yuksel M (2002) Tracheobronchial foreign body aspiration. In Yuksel M, Kalayci NG (eds), 1 (stedn), Thoracic surgery, Istanbul, 677-689.

9. Ludemann JP, Holinger LD (2000) Management of foreign bodies of the airway In: Shields TW, LoCicero J, Ponn RB (eds) General Thoracic Surgery (5thedn), Philadelphia: WB Saunders, 73: 853-862.

10. Wiseman NE (1984) The diagnosis of foreign body aspiration in childhood. J Pediatr Surg 19: 531-535.

11. Senkaya I, Sagdic K, Gebitekin C, Yilmaz M, Ozkan H, et al. (1997) Management of foreign body aspiration in infancy and childhood. A life-threatening problem. Turk J Pediatr 39: 353-362.

12. Darrow DH, Hollinger LD (1996) Foreign bodies in the larynx, trachea, and bronchi. In: Bluestone CD, Stool S,Kenna MA (eds), Pediatric Otolaryngology Philadelphia: WB Saunders, 1390-1401.

13. Gurses D, Akcay A, Cakalar I, Kilis I, Ergin H, et al. (2004) Evaluation of foreign body aspirations in childhood. Child J 4: 98-101.

14. Carluccio F, Romeo R (1997) [Inhalation of foreign bodies: epidemiological data and clinical considerations in the light of a statistical review of 92 cases]. Acta Otorhinolaryngol Ital 17: 45-51.

15. Yildirim M, Dogusoy I, Okay T, Yasaroglu M, Demirbag H, et al. (2003) Tracheobronchial foreign bodies. Turk Journal of Thoracic and Cardiovascular Surgery 11: 228-231.

16. Bhatia PL (1991) Problems in the management of aspirated foreign bodies. West Afr J Med 10: 158-167.

17. Wiseman NE (1984) The diagnosis of foreign body aspiration in childhood. $J$ Pediatr Surg 19: 531-535.

18. Oguz F, Citak A, Unuvar E, Sidal M (2000) Airway foreign bodies in childhood Int J Pediatr Otorhinolaryngol 52: 11-16.

19. Metrangelo S, Monetti C, Meneghini L, Zadra N, Giusti F (1999) Eight years' 
Citation: Yetim TD, Bayarogulları H, Arıca V, Akcora B, Arıca SG, et al. (2012) Foreign Body Aspiration in Children; Analysis of 42 Cases. J Pulmon Resp Med 2:121. doi:10.4172/2161-105X.1000121

experience with foreign-body aspiration in children: what is really important for a timely diagnosis? J Pediatr Surg 34: 1229-1231.

20. Pasaoglu I, Dogan R, Demircin M, Hatipoglu A, Bozer AY (1991) Bronchoscopic removal of foreign bodies in children: retrospective analysis of 822 cases. Thorac Cardiovasc Surg 39: 95-98.

21. Erikçi V, Karaçay S, Arikan A (2003) Foreign body aspiration: a four-years experience. Ulus Travma Acil Cerrahi Derg 9: 45-49.

22. Kolbakir F, Keçelioglu T, Arikan A (1994) Retrospective analysis of 152 cases of bronchoscopy for suspected foreign body aspiration. Turkish Journal of Thoracic and Cardiovascular Surgery 2: 18-25.
23. Puhakka H, Kero P, Erkinjuntti M (1987) Pediatric bronchoscopy during a 17year period. Int J Pediatr Otorhinolaryngol 13: 171-180.

24. Mantor PC, Tuggle DW, Tunell WP (1989)An appropriate negative bronchoscopy rate in suspected foreign body aspiration. Am J Surg 158: 622-624.

25. Munkel WI (1994) Neglect and Abandonment. Child Maltreatment, Brodeur AE Eds, GW medical Publishing St.Louis, 241-258.

26. Veras TN, Hornburg G, Schner AM, Pinto LA (2009) Use of virtual bronchoscopy in children with suspected foreign body aspiration. J Bras Pneumol 35: 937941 